\title{
Experimental Study on Secondary Wear of Friction Pair Surface
}

\author{
Yanqiang Gou, Yuhu Yan \\ College of Mechanical and Electronic Engineering, Shandong University of Science and Technology, Qingdao, China \\ Email: gouyanqiang1993@163.com,2554308206@qq.com
}

How to cite this paper: Gou, Y.Q. and Yan, Y.H. (2019) Experimental Study on Secondary Wear of Friction Pair Surface. World Journal of Engineering and Technology, 7, 513-519. https://doi.org/10.4236/wjet.2019.73036

Received: July 27, 2019

Accepted: August 18, 2019

Published: August 21, 2019

Copyright ( 2019 by author(s) and Scientific Research Publishing Inc. This work is licensed under the Creative Commons Attribution International License (CC BY 4.0).

http://creativecommons.org/licenses/by/4.0/

\section{cc) (i) Open Access}

\begin{abstract}
The phenomenon that the hard abrasive grains repeatedly cut the surface material of the parts during wear is very common in wear. In order to study the influencing factors of mechanical damage, based on the three-body abrasive wear, this paper discusses the wear of the secondary cutting abrasive. Firstly, the secondary wear model of the hemispherical abrasive grain on the friction pair surface is established. Secondly, the simulation experiment is carried out on the secondary scratching of the abrasive wear on the surface of the part. Next, the equivalent strain data and the equivalent stress data obtained by the experiment are subjected to secondary friction analysis. The final results show that the secondary friction damage of the hemispherical abrasive grain is greater than one wear.
\end{abstract}

\section{Keywords}

Hemispherical Abrasive Grain, Wear, Friction

\section{Introduction}

In the three-body abrasive wear, the abrasive particles are loosely distributed on the worn surface. When the abrasive particles are scratched by the contact surface, the wear is highly random, and the result is unpredictable [1]. Therefore, in the three-body abrasive wear, it is very meaningful to study the factors affecting the friction and wear of mechanical equipment.

For example, the process of contact between abrasive grains and wear materials was discussed in [2], and the wear of the abrasive grains and the deformation process of the material surface were obtained. The spherical abrasive particle model and the fractal abrasive particle model were used to analyze the influence of the distribution of the abrasive surface contact zone on the metal surface in [3]. A fractal model was proposed based on the wear rate of abrasive wear 
on rough surfaces [4] [5]. [6] studied the wear behavior of different metal materials. According to the shape of the abrasive grains, the abrasive grains were simplified into spherical abrasive grains [7], conical abrasive grains [7], round table abrasive grains [8], and pyramid abrasive grains [9]. The different wear factors of the above abrasive particles are based on the wear of the smooth plane, ignoring the effects of repeated scratches. Then, whether repeated friction and one friction will cause different wear changes has attracted our attention. This paper mainly analyzes the hemispherical abrasive particles and studies the secondary friction of the abrasive particles.

For the case of three-body abrasive wear, this paper studies the hemispherical abrasive wear model. The ABAQUS finite element software is used to simulate the abrasive wear process, and the influence of secondary friction and wear is analyzed. It is found that the secondary wear is more serious on the metal surface.

\section{Hemispherical Abrasive Grain Model}

The hemispherical abrasive model is shown in Figure 1. The parameter is set to the diameter of $20 \mu \mathrm{m}$ and the height of $18 \mu \mathrm{m}$. The coordinates of the abrasive grain apex are $(0,0,10)$.

The entire cutting process is set up by 4 steps. Step 1 , the abrasive grains are displaced by $2 \mu \mathrm{m}$ in the negative direction of the $\mathrm{Y}$-axis to simulate the case where the abrasive grains are pressed into the surface of the part. Step 2, the abrasive grains are displaced by $80 \mu \mathrm{m}$ in the positive direction of the $\mathrm{Z}$-axis, which is the first cutting of the abrasive grains on the surface of the part. Step 3, the abrasive grains are displaced by $2 \mu \mathrm{m}$ in the negative direction of the Y-axis, which is the starting state of the second cutting. Step 4 , the abrasive grains are displaced by $80 \mu \mathrm{m}$ in the negative direction of the Z-axis, which is the second cutting of the abrasive grains on the surface of the part. The trajectory of the hemispherical abrasive particles is shown in Figure 2.

In order to calculate the average speed of each step, the parameters are set as follows. In step 1, the abrasive grain velocity is $2 \mathrm{~m} / \mathrm{s}$, and the direction is the negative direction of the Y-axis. In step 2, the abrasive cutting speed is $80 \mathrm{~m} / \mathrm{s}$

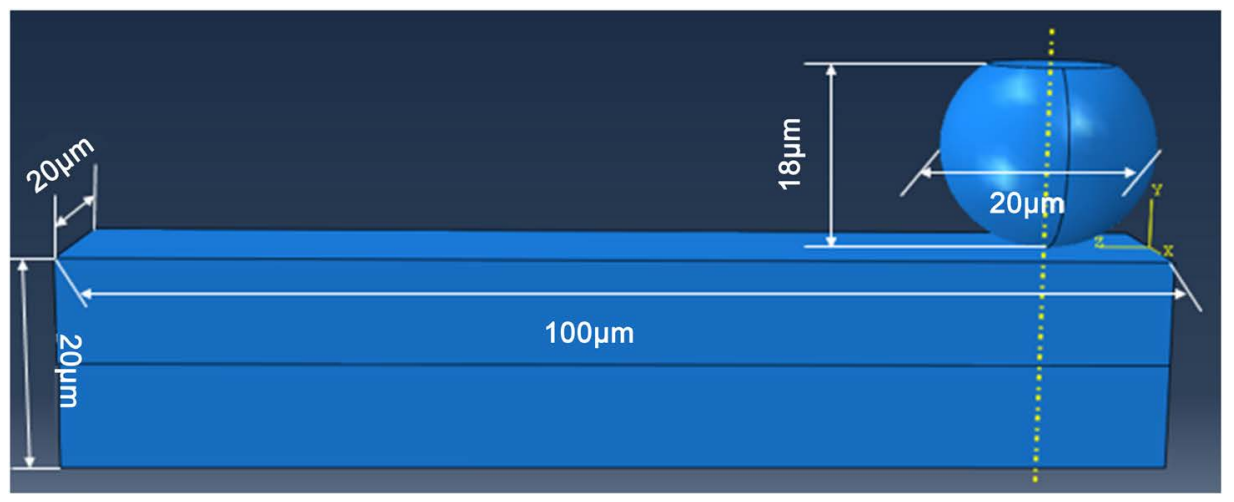

Figure 1. Hemispherical abrasive particles and parts assembly. 


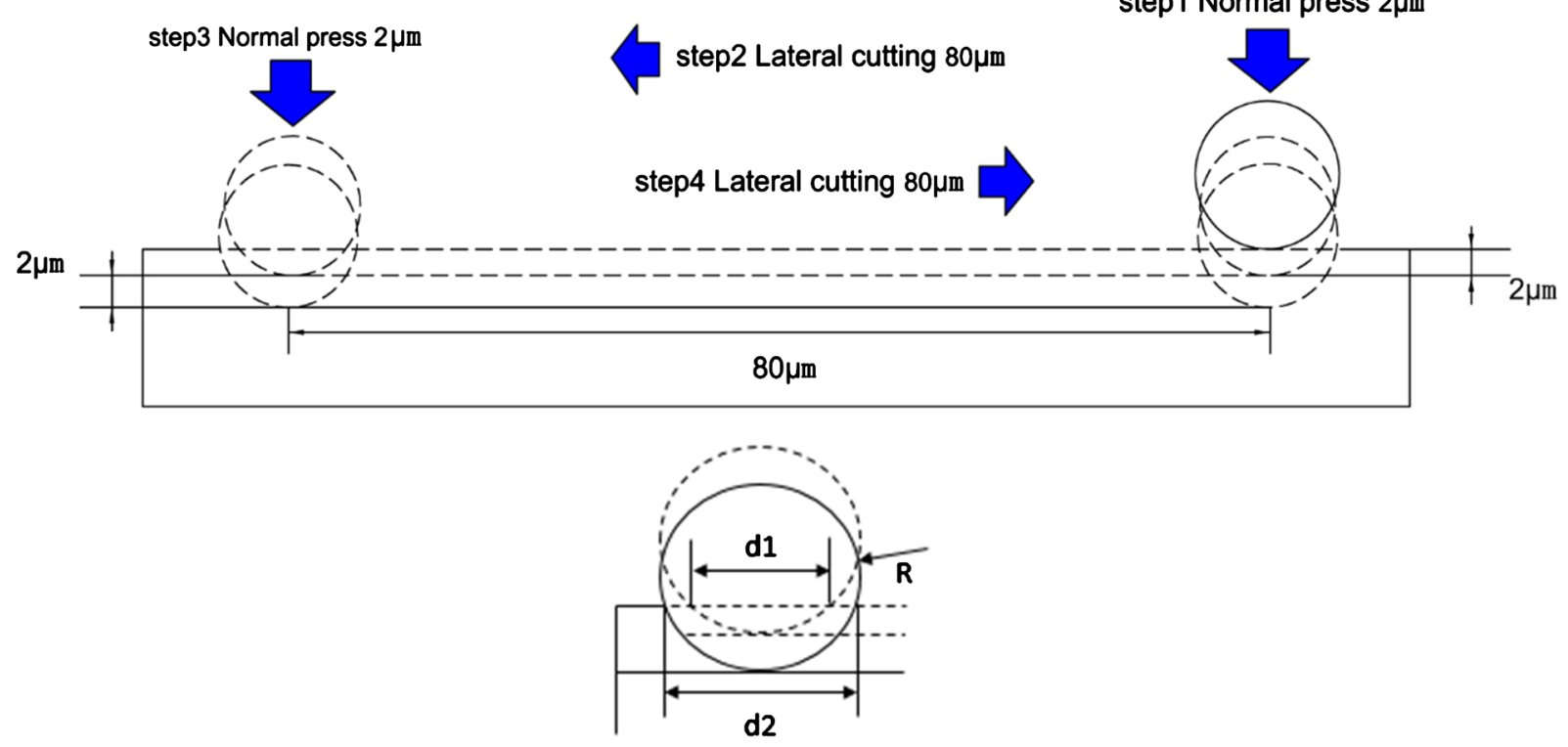

Figure 2. Abrasive displacement diagram.

and the direction is the positive $\mathrm{Z}$-axis. In step 3, the abrasive grain velocity is 2 $\mathrm{m} / \mathrm{s}$, and the direction is the negative direction of the Y-axis. In step 4, the abrasive grain velocity is $80 \mathrm{~m} / \mathrm{s}$, and the direction is the Z-axis negative direction. After the cutting process is completed, the coordinates of the apex of the abrasive grain are $(0,-4,10)$.

The secondary cutting wear rate formula is as follows [10]:

$$
H=R^{2}\left\{\arcsin \left(\frac{d_{2}}{2 R}\right)+\frac{d_{2}}{2 R}\left[1-\left(\frac{d_{1}}{2 R}\right)^{2}\right]^{\frac{1}{2}}-\arcsin \left(\frac{d_{1}}{2 R}\right)-\frac{d_{2}}{2 R}\left[1-\left(\frac{d_{2}}{2 R}\right)^{2}\right]^{\frac{1}{2}}\right\}
$$

where $d_{1}$ is the width of the furrow when the abrasive grain first cuts the surface material of the part, and $d_{2}$ is the width of the furrow when the abrasive grain cuts the surface material of the part for the second time.

\section{Simulation Experiments}

We set the surface material of the part to the aluminum alloy material. The first cut is taken as a reference and compared with the second cut.

\subsection{Equivalent Plastic Strain Analysis}

The abrasive particles and the surface material of the component are provided by the aluminum alloy material. The strain state cloud of the entire model at the end of each analysis step is shown in Figure 3. The maximum equivalent strain data is shown in Table 1.

The following analysis can be derived from the data in Table 1. At step 1, the equivalent strain data increases with time. In the initial stage of step 2 abrasive grain cutting, the maximum equivalent strain data increases slightly with time. In step 3, continue to squeeze the surface of the part along the normal direction, 


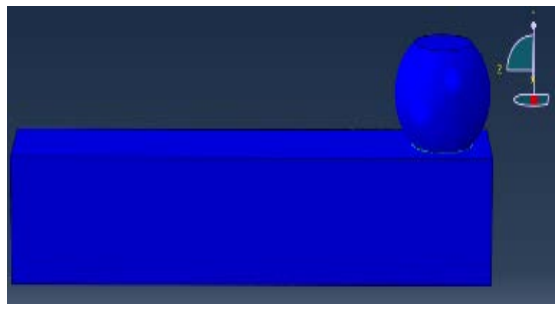

(a)

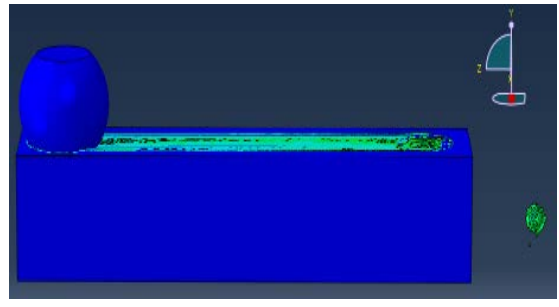

(c)

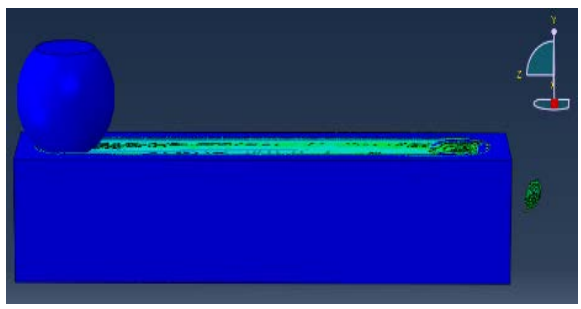

(b)

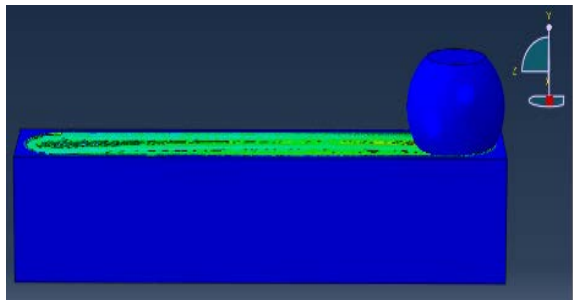

(d)

Figure 3. Hemispherical abrasive grain equivalent plastic strain cloud. (a) The end of step1; (b) The end of step 2; (c) The end of step 3; (d) The end of step 4.

Table 1. Hemispherical abrasive grain maximum equivalent plastic strain data.

\begin{tabular}{|c|c|c|c|c|c|}
\hline $\begin{array}{l}\text { Incremental step } \\
\text { (Increment) }\end{array}$ & $\begin{array}{c}\text { Times } \\
(\mu \mathrm{s})\end{array}$ & $\begin{array}{c}\text { Step } 1 \\
\text { PEEQ (\%) }\end{array}$ & $\begin{array}{c}\text { Step } 2 \\
\text { PEEQ (\%) }\end{array}$ & $\begin{array}{c}\text { Step } 3 \\
\text { PEEQ (\%) }\end{array}$ & $\begin{array}{c}\text { Step } 4 \\
\text { PEEQ (\%) }\end{array}$ \\
\hline 0 & 0 & 0 & 0.7676 & 0.7887 & 0.7909 \\
\hline 222 & 0.05 & 0.05203 & 0.7712 & 0.7889 & 0.7909 \\
\hline 444 & 0.1 & 0.09822 & 0.7716 & 0.7889 & 0.7909 \\
\hline 666 & 0.15 & 0.1448 & 0.7733 & 0.7889 & 0.7910 \\
\hline 888 & 0.2 & 0.2000 & 0.7735 & 0.7892 & 0.7910 \\
\hline 1110 & 0.25 & 0.2707 & 0.7779 & 0.7893 & 0.7910 \\
\hline 1332 & 0.3 & 0.4804 & 0.7790 & 0.7894 & 0.7910 \\
\hline 1554 & 0.35 & 0.5625 & 0.7818 & 0.7894 & 0.7910 \\
\hline 1776 & 0.4 & 0.6070 & 0.7837 & 0.7897 & 0.7910 \\
\hline 1998 & 0.45 & 0.6385 & 0.7857 & 0.7898 & 0.7910 \\
\hline 2220 & 0.5 & 0.6942 & 0.7857 & 0.7898 & 0.7911 \\
\hline 2442 & 0.55 & 0.7135 & 0.7857 & 0.7899 & 0.7911 \\
\hline 2664 & 0.6 & 0.7420 & 0.7861 & 0.7901 & 0.7911 \\
\hline 2886 & 0.65 & 0.7278 & 0.7866 & 0.7902 & 0.7911 \\
\hline 3108 & 0.7 & 0.7486 & 0.7870 & 0.7909 & 0.7911 \\
\hline 3330 & 0.75 & 0.7498 & 0.7872 & 0.7909 & 0.7911 \\
\hline 3552 & 0.8 & 0.7676 & 0.7876 & 0.7909 & 0.7911 \\
\hline 3774 & 0.85 & 0.7823 & 0.7880 & 0.7909 & 0.7911 \\
\hline 3996 & 0.9 & 0.7853 & 0.7881 & 0.7909 & 0.7911 \\
\hline 4218 & 0.95 & 0.7742 & 0.7883 & 0.7909 & 0.7911 \\
\hline 4440 & 1 & 0.7676 & 0.7887 & 0.7909 & 0.5845 \\
\hline
\end{tabular}


and the equivalent strain data changes little. In step 4, the abrasive grains are cut in the furrow, and the residual stress of the fracture surface of the furrow is superimposed with the cutting force, so that the secondary cutting strain data is larger than one cutting. When the abrasive particles are displaced to a distance of $2 \mu \mathrm{m}$ from the initial position, the equivalent plastic strain value drops sharply.

\subsection{Equivalent Stress Analysis}

The equivalent stress change of the model after the end of the four analysis steps is shown in Figure 4. The equivalent stress data collected is shown in Table 2.

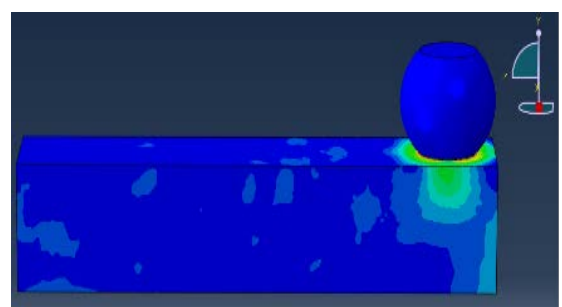

(a)

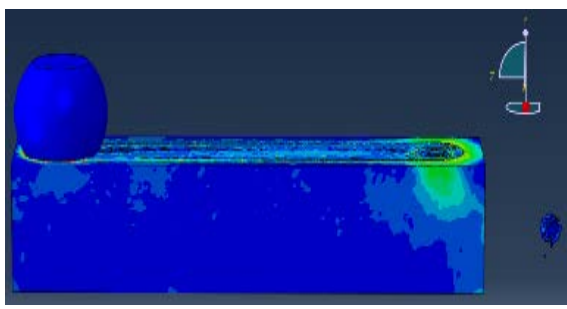

(c)

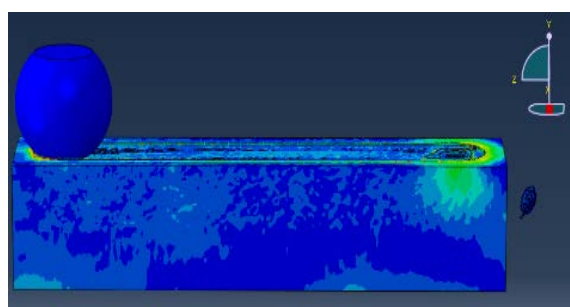

(b)

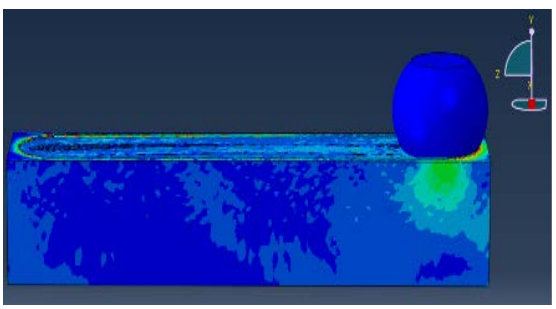

(d)

Figure 4. Hemispherical abrasive grain maximum equivalent stress cloud. (a) The end of step 1; (b) The end of step 2; (c) The end of step3; (d) The end of step 4.

Table 2. Hemispherical abrasive grain maximum equivalent stress data.

\begin{tabular}{cccccc}
\hline $\begin{array}{c}\text { Incremental step } \\
\text { (Increment })\end{array}$ & $\begin{array}{c}\text { Times } \\
(\mu \mathrm{s})\end{array}$ & $\begin{array}{c}\text { Step 1 } \\
\text { Mises (MPa) }\end{array}$ & $\begin{array}{c}\text { Step 2 } \\
\text { Mises (MPa) }\end{array}$ & $\begin{array}{c}\text { Step 3 } \\
\text { Mises (MPa) }\end{array}$ & $\begin{array}{c}\text { Step 4 } \\
\text { Mises (MPa) }\end{array}$ \\
\hline 0 & 0 & 0 & 397.6 & 386.8 & 390.9 \\
222 & 0.05 & 346.3 & 387.4 & 385.5 & 383.8 \\
444 & 0.1 & 349.4 & 387.2 & 384.7 & 387.2 \\
666 & 0.15 & 355.3 & 394.6 & 387.3 & 386.1 \\
888 & 0.2 & 360.9 & 395.4 & 384.0 & 384.1 \\
1110 & 0.25 & 364.3 & 394.4 & 386.2 & 385.0 \\
1332 & 0.3 & 379.5 & 397.0 & 383.8 & 386.5 \\
1554 & 0.35 & 389.8 & 396.9 & 386.2 & 390.5 \\
1776 & 0.4 & 390.9 & 394.1 & 389.7 & 389.1 \\
1998 & 0.45 & 398.5 & 388.7 & 386.0 & 391.2 \\
2220 & 3962.8 & 389.2 & 387.8 & 386.2 \\
\hline
\end{tabular}




\begin{tabular}{cccccc} 
Continued & \multicolumn{5}{l}{} \\
\hline 2664 & 0.6 & 400.4 & 387.4 & 393.0 & 384.2 \\
2886 & 0.65 & 400.1 & 385.0 & 388.5 & 388.3 \\
3108 & 0.7 & 401.9 & 383.7 & 393.6 & 385.1 \\
3330 & 0.75 & 401.3 & 397.6 & 392.1 & 388.9 \\
3552 & 0.8 & 403.6 & 397.8 & 390.8 & 389.7 \\
3774 & 0.85 & 402.2 & 387.8 & 389.2 & 392.8 \\
3996 & 0.9 & 402.2 & 384.4 & 392.3 & 392.1 \\
4218 & 0.95 & 402.0 & 385.3 & 395.7 & 399.9 \\
4440 & 1 & 397.6 & 386.8 & 390.9 & 391.9 \\
\hline
\end{tabular}

The following analysis is obtained by Table 2 . At step 1 , the equivalent stress increases with time. In the first stage of step 2 abrasive grain cutting, the maximum equivalent stress data varies less. In step 3, the surface of the part is continuously pressed in the direction of the method, and the equivalent stress is slightly increased. In step 4, the abrasive particles undergo a cutting action in the furrow and the equivalent stress level is lower overall than step 2.

\section{Conclusions}

1) In three-body abrasive wear, analysis of equivalent strain data and equivalent stress data indicates that secondary wear is greater than one wear. Therefore, the wear of the friction pair surface is related to the number of frictions.

2) There are many factors affecting the wear of metal surfaces. We further explore other wear factors of hemispherical abrasive grains in the future.

\section{Acknowledgements}

The authors are grateful for the support provided by the China Coal Industry Association Science and Technology Guiding Program (MTKJ 2012-344).

\section{Conflicts of Interest}

The authors declare no conflicts of interest regarding the publication of this paper.

\section{References}

[1] Yuan, C., Wang, Z. and Zhou, Z. (2008) Wear Surface of Sliding Bearing and Its Abrasive Grain Characteristics under Different Wear Modes. Lubrication \& Sealing, 12, 21-24.

[2] Fan, Y., Yang, X. and Li, Z. (2005) Finite Element Analysis of Microscopic Contact Process in Abrasive Wear. Journal of Mechanical Engineering, 41, 35-37.

[3] Zhang, Y., Wang, J. and Chen, F. (2018) Contact Analysis of Abrasive Wear. Lubrication and Sealing, 43, 11-16.

[4] Wang, X. and Zhang, W. (2002) Abrasive Wear Model Based on Fractal Theory. 
Lubrication \& Sealing, 3, 2-4.

[5] Ding, X., Zhang, Z. and Ren, Q. (2016) Prediction Model of Abrasive Wear Based on Fractal Theory. Journal of Gansu Sciences, 28, 84-88.

[6] Yi, D., Xing, J. and Fu, H. (2015) Investigations on Microstructures and Three-Body Abrasive Wear Behaviors of Fe-B Cast Alloy Containing Cerium. Tribology Letters, 58, 21. https://doi.org/10.1007/s11249-015-0501-x

[7] Hisakado, T. and Suda, H. (1999) Effects of Asperity Shape and Summit Height Distributions on Friction and Wear Characteristics. Wear, 225-229, 450-457.

[8] Liu, S. (2002) Study of Plowing and Friction at the Surfaces of Plastic Deformed Metals. Tribology International, 35, 511-522.

[9] Torrance, A. (2005) Modelling Abrasive Wear. Wear, 258, 281-293. https://doi.org/10.1016/j.wear.2004.09.065

[10] Benabdallah, S. and Chalifoux, J. (1989) Ploughing of Soft Asperities by a Hemispherical Slider. Tribology International, 22, 383-388.

https://doi.org/10.1016/0301-679X(89)90070-4 